\title{
(2) OPEN ACCESS \\ Risk factors for intellectual disability in children with spastic cerebral palsy
}

\author{
David Cummins, ${ }^{1}$ Claire Kerr 0 (ㄱ, ${ }^{2}$ Karen McConnell, ${ }^{2}$ Oliver Perra ${ }^{2}$
}

- Additional material is published online only. To view, please visit the journal online (http://dx.doi.org/10.1136/ archdischild-2020-320441).

${ }^{1}$ Royal Jubilee Maternity Service, Belfast, UK

${ }^{2}$ School of Nursing and Midwifery, Queen's University Belfast, Belfast, UK

Correspondence to Dr Claire Kerr, School of Nursing and Midwifery, Queen's University Belfast, Belfast BT9 7BL, UK; c.kerr@qub.ac.uk

Received 10 August 2020 Revised 11 January 2021 Accepted 23 January 2021 Published Online First 16 March 2021

\section{Check for updates}

(c) Author(s) (or their employer(s)) 2021. Re-use permitted under CC BY-NC. No commercial re-use. See rights and permissions. Published by BMJ.

To cite: Cummins D, Kerr C, McConnell K, et al.

Arch Dis Child

2021:106:975-980.

\section{ABSTRACT}

Background Cerebral palsy (CP) is a non-progressive disorder of posture and movement caused by prenatal or perinatal lesions of the brain. Children with $\mathrm{CP}$ are also at increased risk of other disabilities, for example, intellectual disability. Previous studies suggest the risk of intellectual disability varies in complex ways according to the type of motor impairment and perinatal factors such as gestational age.

Objective To determine the patterns of risk of intellectual disability in children with spastic CP. Design Cross-sectional, population-based study using the Northern Ireland Cerebral Palsy Register.

Participants Persons born in 1981-2008 with congenital bilateral or unilateral spastic $\mathrm{CP}(\mathrm{N}=1452)$. Outcome measure The outcome measure was severe intellectual disability (IQ $<50)$, as reported by clinicians known to the child. Data pertaining to CP subtype, sex, gestational age, birth weight and functional level were included in analyses.

Results Severe intellectual disability was significantly more prevalent in children with bilateral spastic $C P$ (BSCP) compared with children with unilateral spastic CP $\left(\chi^{2}(2)=162.60, p<0.001\right)$. Compared with very preterm infants with $\mathrm{BSCP}$, the risk of intellectual disability increased in moderately preterm $(\mathrm{OR}=3.97,95 \% \mathrm{Cl} 1.04$ to 15.23$)$ and at-term (OR=2.51,95\% $\mathrm{Cl} 1.16$ to 5.44$)$ children with BSCP.

Conclusions Children with BSCP are at increased risk of intellectual disability, with those born at term at the highest risk. The findings highlight the importance of early screening, particularly for children with BSCP born at term.

\section{INTRODUCTION}

Cerebral palsy (CP) is described 'as a group of permanent disorders of the development of movement and posture causing activity limitations that are attributed to non progressive disturbances occurring in the developing fetal or infant brain'. The aetiology is multifactorial; however, the largest risk factor is extreme prematurity, with $10 \%$ risk in babies born before 28 weeks gestation compared with $0.1 \%$ risk in term infants. ${ }^{2}$ Recent reports from Europe $^{3}$ and Australia ${ }^{4}$ suggest prevalence of CP is declining; European rates decreased from 1.9 per 1000 live births in 1980 to 1.77 in $2003,{ }^{3}$ whereas in Australia rates decreased from 2.1 per 1000 live births in 1995-1997 to 1.4 for birth years 2010-2012. ${ }^{4}$

The Surveillance of Cerebral Palsy in Europe (SCPE) collaboration defines three CP subtypes based on predominant neurological findings: spastic,

\section{What is already known on this topic?}

- Children with bilateral spastic cerebral palsy display risk for intellectual disability.

- The factors explaining this risk are not fully understood.

\section{What this study adds?}

- Risk of intellectual disability in bilateral spastic cerebral palsy increases in infants born at term.

- This knowledge will enable healthcare professionals to more easily identify children with cerebral palsy at higher risk of intellectual disability, facilitating early referral to appropriate specialists.

ataxic and dyskinetic. ${ }^{5}$ Spastic $\mathrm{CP}$, accounting for over $75 \%$ of all cases of $\mathrm{CP}$, is characterised by increased muscle tone and the presence of pathological reflexes, resulting in abnormal patterns of movement and posture. ${ }^{5}$ The SCPE further distinguishes between unilateral spastic CP (USCP), where one side of the body is affected, and bilateral spastic CP (BSCP), where both sides of the body are involved. $^{5}$

In addition to motor impairment, individuals with $\mathrm{CP}$ are also at risk of intellectual disability. In the USA, the prevalence of intellectual disability in CP was reported as 12.1-12.2 per 1000 cases, ${ }^{6}$ and compared with the general population children with CP display lower median IQ scores. ${ }^{7-9}$ As motor and intellectual abilities influence each other, particularly in early developmental stages, ${ }^{10} 11$ it is perhaps unsurprising that more severe motor difficulties have been shown to be related to intellectual disability $^{7-9} 12$ and that intellectual disability is more common in children with BSCP compared with children with USCP. ${ }^{13}$ The SCPE defines 'severe' intellectual disability as IQ $<50 .{ }^{3}{ }^{14}$

The association between $\mathrm{CP}$ subtypes and intellectual disability may be further complicated by prematurity. While premature birth is a key risk factor for $\mathrm{CP}^{2}$ prematurity is also associated with increased risk of intellectual delay and lower educational attainment. ${ }^{15}$ Studies ${ }^{16}{ }^{17}$ have suggested that, for children with $\mathrm{CP}$, the risk of intellectual disability associated with prematurity may differ depending on the type of CP. In children with BSCP, a greater risk of intellectual disability was observed with increased gestational age $(\mathrm{GA})^{16}$ or among children with normal birth weight. ${ }^{17}$ Some 
studies ${ }^{18} 19$ have suggested that preterm birth confers higher risk of intellectual delay than very low birth weight, but the issue has not been sufficiently investigated in children with CP.

The evidence discussed above suggests that understanding the patterns of risk of intellectual disability across CP subtypes necessitates going beyond the associations between risk factors and the outcome, to investigate the way in which prematurity may moderate these associations. In this study we extend previous work ${ }^{16}{ }^{17}$ by investigating perinatal factors for intellectual disability in children with CP using a large sample from a national CP register. We focused on the most common CP types, BSCP and USCP, as well as perinatal factors such as GA and standardised birth weight. Standardised birth weight represents deviations from the child's expected weight for their GA, thus acting as a proxy for growth anomalies. The outcome of interest in this study was severe intellectual disability.

The objectives of this paper were to:

- Describe the association between spastic CP subtypes and severe intellectual disability across GA categories, standardised birthweight scores, motor severity of CP and participants' sex.

- Investigate how GA categories moderate the association between spastic CP subtypes and severe intellectual disability, while controlling for standardised birthweight scores and participants' sex.

\section{METHODS}

\section{Study design and setting}

This is a population-based, cross-sectional study using data from the Northern Ireland Cerebral Palsy Register (NICPR). The NICPR is a confidential record of children with CP in Northern Ireland since 1977 . CP cases are notified by multiple informants (eg, healthcare professionals, special needs schools and so on). CP diagnosis and motor and other impairments are reported by a professional known to the child through a standardised assessment form, and these forms are further checked for consistency and completeness by the NICPR's paediatrician. Diagnosis ascertainment typically occurs after the child's fourth birthday, in line with the SCPE recommendations. Confirmed CP cases are not followed up after ascertainment.

\section{Participants}

Participants were 1452 individuals with prenatal or perinatal spastic CP born in 1981-2008. Excluded from analyses were 437 individuals with CP born during the same birth year period: 19 who died before the age of 2 years; 139 whose diagnosis was not confirmed by the child's fifth birthday; 126 who had postneonatally acquired CP; 122 with dyskinetic, ataxic or unclassifiable CP; and 31 for whom information on CP type was not provided.

\section{Variables}

Intellectual disability was estimated by the notifying healthcare professional as present or absent, and if present whether 'severe' (IQ <50). ${ }^{14}$ Gestational age (GA) was categorised as very preterm (VPT), that is, $<32$ completed weeks gestation; moderately preterm (MPT), that is, 32-36 completed weeks gestation; and term $(\mathrm{T})$, that is, $\geq 37$ weeks gestation. Standardised birthweight scores ( $z \mathrm{BW}$ ) were calculated using Gardosi norms for single births ${ }^{20}$ or adjusted norms for multiple births ${ }^{21}$; these scores indicate deviations from the normative birth weight for sex and GA, according to birth type. Sex was coded to compare male against female. Motor severity of the child's CP was classified using the Gross Motor Function Classification System (GMFCS). 2223

\section{Data analysis}

Demographic and clinical characteristics were summarised using descriptive statistics. Cross-tabulations and Pearson's $\chi^{2}$ tests were used to explore the associations between variables. We used multilevel logistic regressions to test the associations between intellectual disability and covariates spastic CP subtype and prematurity, while controlling for other covariates $(z \mathrm{BW}$ and sex). Multilevel models allowed controlling for variability across birth year cohorts. Diagnostic checks (numerical problems and sparsely populated cells, specification error, multicollinearity, and the presence of influential observations) were performed on the logistic regression models to ensure assumptions were met; all these checks were satisfactory. A further multilevel logistic regression model tested if the association between spastic CP subtype and severe intellectual disability was moderated by prematurity. To this end, we included an interaction term representing spastic CP subtype by GA categories. Results are summarised by OR, indicating the change in the odds of severe intellectual disability associated with a predictor.

Complete data on intellectual disability and other covariates included in the models were available from 1271 cases. To avoid bias due to non-response and missing information, we used a multiple imputation (MI) approach ${ }^{24}$ and ran the logistic regression models on $M=50$ imputed data sets created using chained equations (see online supplemental appendix). When assumptions underlying MI are tenable (see online supplemental appendix), MI provides more reliable estimates compared with traditional approaches to missing data, for example, completecase analyses. ${ }^{25}$ Thus, we report logistic regression results estimated on all cases with complete and incomplete data. Final estimates were combined from the $M=50$ imputed data sets applying combination rules by Rubin. ${ }^{26}$ All analyses were conducted using Stata V.13 software.

\section{RESULTS}

The clinical and demographic characteristics of the individuals in the study are summarised in table 1.

\section{Two-way associations between severe intellectual disability and clinical/demographic variables}

Table 2 displays the proportions of children with severe intellectual disability by clinical and demographic variables. The results suggest a strong association, whereby severe intellectual disability is significantly more prevalent in children with BSCP compared with those with USCP. Further comparisons demonstrated an association between GA and severe intellectual disability. Compared with other GA categories, severe intellectual disability was more likely in infants born at term: $31 \%$ of children with spastic CP born at term had severe intellectual disability, compared with $14 \%$ and $23 \%$ among children born MPT and VPT, respectively. There was also a significant association between categories of $z$ BW and severe intellectual disability, whereby infants smaller for GA ( -2 SD points or more) were at higher risk; for example, $36 \%$ of those with BW below 2 SD displayed severe intellectual disability, compared with $26 \%$ of those with normative BW for GA $( \pm 1 S D)$. No significant associations between severe intellectual disability and sex were reported, whereas severe intellectual disability was strongly associated with higher levels of GMFCS. 


\begin{tabular}{|c|c|}
\hline Characteristics & n (\%) \\
\hline \multicolumn{2}{|l|}{ CP subtype } \\
\hline $\mathrm{BSCP}$ & $824(56.75)$ \\
\hline USCP & $628(43.25)$ \\
\hline \multicolumn{2}{|l|}{ Intellectual disability } \\
\hline None & 842 (57.99) \\
\hline Mild & $200(13.77)$ \\
\hline Severe & $387(26.65)$ \\
\hline Missing information & $23(1.58)$ \\
\hline \multicolumn{2}{|l|}{ Gestational age } \\
\hline VPT (<32 weeks) & $381(26.24)$ \\
\hline MPT (32-36+6 weeks) & $239(16.46)$ \\
\hline $\mathrm{T}$ ( $\geq 37$ weeks) & 748 (51.52) \\
\hline Missing information & $84(5.79)$ \\
\hline \multicolumn{2}{|l|}{$z \mathrm{BW}$} \\
\hline-2 SD or less & $183(12.60)$ \\
\hline-2 to -1 SD & 267 (18.39) \\
\hline-1 to +1 SD & $620(42.70)$ \\
\hline+1 to +2 SD & $128(8.82)$ \\
\hline$+2 \mathrm{SD}$ or more & $88(6.06)$ \\
\hline Missing information & $166(11.43)$ \\
\hline \multicolumn{2}{|l|}{ Sex } \\
\hline Male & 837 (57.64) \\
\hline Female & $615(42.36)$ \\
\hline \multicolumn{2}{|l|}{ GMFCS } \\
\hline I & $274(18.87)$ \\
\hline II & 646 (44.49) \\
\hline III & $138(9.5)$ \\
\hline IV & 95 (6.54) \\
\hline V & $295(20.32)$ \\
\hline Missing data & $4(0.28)$ \\
\hline \multicolumn{2}{|l|}{ Multiple births } \\
\hline No & $1329(91.53)$ \\
\hline Yes & $123(8.47)$ \\
\hline
\end{tabular}

BSCP, bilateral spastic cerebral palsy; CP, cerebral palsy; GMFCS, Gross Motor Function Classification System; MPT, moderately preterm; T, term; USCP, unilateral spastic cerebral palsy; VPT, very preterm; z BW, standardised birthweight scores.

\section{Adjusted associations between severe intellectual disability, $\mathrm{GA}$ and $z$ BW}

The initial logistic regression model revealed a good fit $(F(5,65$ $412.4)=33.15, p<0.001)$. The results confirmed a strong relationship between BSCP and severe intellectual disability, whereby individuals with BSCP displayed a sevenfold increase in the odds of severe intellectual disability compared with those with USCP $(\mathrm{OR}=7.43,95 \% \mathrm{CI} 5.42$ to 10.20$)$. The results also indicated an association between GA and severe intellectual disability. Infants born at term displayed a twofold increase in the odds of severe intellectual disability compared with VPT infants $(\mathrm{OR}=2.49$, $95 \%$ CI 1.80 to 3.45). A marginal association was demonstrated between $z \mathrm{BW}$ and severe intellectual delay. A 1 SD-unit reduction in GA-adjusted BW was associated with approximately $9 \%$ increase in the odds of severe intellectual disability $(\mathrm{OR}=1.09$, $95 \%$ CI 1.00 to 1.18). The association between severe intellectual disability and sex was not significant $(\mathrm{OR}=1.02,95 \% \mathrm{CI}$ 0.78 to 1.33 ).

A successive model tested whether the association between spastic CP type and severe intellectual disability was conditional on GA. The inclusion of the interaction term indicated excellent model fit $(F(7,65279.9)=24.22, \mathrm{p}<0.0001)$. The parameters of the model are reported in table 3 . The significant interaction
Table 2 Severe intellectual disability in children with spastic CP by clinical and demographic characteristics

\begin{tabular}{|c|c|c|c|}
\hline \multirow[b]{2}{*}{ Characteristics } & \multicolumn{3}{|c|}{ Severe intellectual disability } \\
\hline & Yes, $n$ (\%) & No, $n(\%)$ & Total, n (\%) \\
\hline \multicolumn{4}{|l|}{ CP subtype } \\
\hline BSCP & $326(40.15)$ & $486(59.85)$ & $812(56.82)$ \\
\hline USCP & $61(9.89)$ & 556 (90.11) & $617(43.18)$ \\
\hline Total & $387(27.08)$ & $1042(72.92)$ & $1429(100.00)$ \\
\hline \multicolumn{4}{|c|}{$\chi^{2}(1)=162.58, p<0.001$} \\
\hline \multicolumn{4}{|l|}{ Gestational age } \\
\hline VPT & $81(22.56)$ & $295(78.46)$ & $376(27.81)$ \\
\hline MPT & $50(13.93)$ & $186(78.81)$ & $236(17.46)$ \\
\hline $\mathrm{T}$ & $228(30.81)$ & $512(69.19)$ & $740(54.73)$ \\
\hline Total & 359 (26.55) & $993(73.45)$ & $1352(100.00)$ \\
\hline \multicolumn{4}{|c|}{$\chi^{2}(2)=15.20, p<0.001$} \\
\hline \multicolumn{4}{|c|}{$z \mathrm{BW}$} \\
\hline$-2 S D$ or less & $66(36.67)$ & $114(63.33)$ & $180(14.16)$ \\
\hline-2 to -1 SD & $75(28.41)$ & $189(71.59)$ & $264(20.77)$ \\
\hline-1 to +1 SD & $159(25.94)$ & $454(74.06)$ & $613(48.23)$ \\
\hline+1 to +2 SD & $30(23.62)$ & 97 (76.38) & $127(9.99)$ \\
\hline $2 \mathrm{SD}$ or more & $19(21.84)$ & $68(78.16)$ & $87(6.85)$ \\
\hline Total & $349(27.46)$ & $922(72.54)$ & $1271(100.00)$ \\
\hline \multicolumn{4}{|c|}{$\chi^{2}(4)=10.81, p=0.029$} \\
\hline \multicolumn{4}{|c|}{ Sex } \\
\hline Male & $231(28.07)$ & $592(71.93)$ & $823(57.59)$ \\
\hline Female & $156(25.74)$ & $450(74.26)$ & $606(42.41)$ \\
\hline Total & $387(27.08)$ & $1042(72.92)$ & $1429(100.00)$ \\
\hline \multicolumn{4}{|c|}{$\chi^{2}(1)=0.96, p=0.33$} \\
\hline \multicolumn{4}{|c|}{ GMFCS } \\
\hline 1 & $11(4.07)$ & $259(95.93)$ & $270(18.93)$ \\
\hline II & $87(13.77)$ & $545(86.23)$ & $632(44.32)$ \\
\hline III & 20 (14.49) & $118(85.51)$ & $138(9.68)$ \\
\hline IV & $36(38.30)$ & $58(61.70)$ & $94(6.59)$ \\
\hline V & $231(79.11)$ & $61(20.89)$ & $292(20.48)$ \\
\hline Total & $385(27.00)$ & $1041(73.00)$ & $1426(100.00)$ \\
\hline \multicolumn{4}{|c|}{$\chi^{2}(4)=547.20, p<0.001$} \\
\hline \multicolumn{4}{|c|}{ Multiple births } \\
\hline No & 355 (27.16) & $952(72.84)$ & 1307 (91.46) \\
\hline Yes & $32(26.23)$ & $90(73.77)$ & $122(8.54)$ \\
\hline Total & $387(27.08)$ & $1042(72.92)$ & $1429(100.00)$ \\
\hline
\end{tabular}

BSCP, bilateral spastic cerebral palsy; CP, cerebral palsy; GMFCS, Gross Motor Function Classification System; MPT, moderately preterm; $T$, term; USCP, unilateral spastic cerebral palsy; VPT, very preterm; $z$ BW, standardised birthweight scores.

between spastic CP type and GA is represented in figure 1. The odds of severe intellectual disability increased substantially for children with BSCP of higher GA compared with children with USCP. A trend was also confirmed for a protective effect of $z$ BW scores.

\section{DISCUSSION}

$\mathrm{CP}$ is a complex condition encompassing a number of impairments including motor, sensory, psychological and intellectual functioning that necessitates a multidisciplinary approach to management. In this study we focused on identification of risk factors for intellectual disability in children with congenital spastic $\mathrm{CP}$ and the interactions between those factors. Our data, derived from a robustly ascertained population-based register, demonstrated severe intellectual disability was present in over a quarter of all children with spastic CP. Severe intellectual disability was more prevalent in children with BSCP compared with USCP, and more likely in children born at 
Table 3 Estimated parameters of the multilevel logistic regression model on $n=1271$ with complete data (A), and on $N=1452$ with complete and incomplete data who provided $M=50$ imputed data sets (B)

\begin{tabular}{|c|c|c|}
\hline Characteristics & OR & $95 \% \mathrm{Cl}$ \\
\hline \multicolumn{3}{|l|}{ (A) $n=1271$ with complete data } \\
\hline \multicolumn{3}{|l|}{ CP subtype } \\
\hline USCP & Reference & - \\
\hline $\mathrm{BSCP}$ & $3.23 * *$ & 1.61 to 6.49 \\
\hline \multicolumn{3}{|l|}{ Gestational age } \\
\hline VPT & Reference & - \\
\hline MPT & 0.32 & 0.08 to 1.18 \\
\hline $\mathrm{T}$ & 1.11 & 0.54 to 2.28 \\
\hline \multicolumn{3}{|l|}{ Birth weight } \\
\hline Lower z BW & $1.08^{+}$ & 0.99 to 1.18 \\
\hline \multicolumn{3}{|l|}{ Sex } \\
\hline Female & Reference & - \\
\hline Male & 1.08 & 0.81 to 1.43 \\
\hline \multicolumn{3}{|l|}{ CP subtype by gestational age } \\
\hline VPT $\times$ BSCP & Reference & - \\
\hline MPT×BSCP & $4.75^{*}$ & 1.17 to 19.25 \\
\hline $\mathrm{T} \times \mathrm{BSCP}$ & $2.84^{*}$ & 1.26 to 6.36 \\
\hline Intercept & $0.10^{* * *}$ & 0.05 to 0.19 \\
\hline Random effect of birth year cohort & Variance & $95 \% \mathrm{Cl}$ \\
\hline Birth year & 0.13 & 0.04 to 0.39 \\
\hline \multicolumn{3}{|c|}{ (B) $\mathrm{N}=1452$ with complete and incomplete data ( $M=50$ imputed data sets) } \\
\hline \multicolumn{3}{|c|}{ CP subtype } \\
\hline USCP & Reference & - \\
\hline BSCP & $3.36^{* * *}$ & 1.73 to 6.53 \\
\hline \multicolumn{3}{|l|}{ Gestational age } \\
\hline VPT & Reference & - \\
\hline MPT & 0.34 & 0.10 to 1.22 \\
\hline $\mathrm{T}$ & 1.16 & 0.58 to 2.30 \\
\hline \multicolumn{3}{|l|}{ Birth weight } \\
\hline Lower z BW & $1.08^{+}$ & 0.99 to 1.18 \\
\hline \multicolumn{3}{|l|}{ Sex } \\
\hline Female & Reference & - \\
\hline Male & 1.03 & 0.79 to 1.35 \\
\hline \multicolumn{3}{|l|}{ CP subtype by gestational age } \\
\hline VPT $\times$ BSCP & Reference & - \\
\hline MPT×BSCP & $3.97^{*}$ & 1.04 to 15.23 \\
\hline $\mathrm{T} \times \mathrm{BSCP}$ & $2.51^{* *}$ & 1.16 to 5.44 \\
\hline Intercept & $0.10^{* * *}$ & 0.05 to 0.19 \\
\hline Random effect of birth year cohort & Variance & $95 \% \mathrm{Cl}$ \\
\hline Birth year & 0.13 & 0.05 to 0.36 \\
\hline
\end{tabular}

${ }^{+} \mathrm{P}<0.10,{ }^{*} \mathrm{P}<0.05,{ }^{* *} \mathrm{P}<0.01,{ }^{* * *} \mathrm{P}<0.001$.

$\mathrm{BSCP}$, bilateral spastic cerebral palsy; CP, cerebral palsy; MPT, moderately preterm; $\mathrm{T}$, term; USCP, unilateral spastic cerebral palsy; VPT, very preterm; z BW, standardised birthweight scores.

term. Furthermore, for children with BSCP, the probability of severe intellectual disability increased with older GA, whereas it remained similar across GA categories for children with USCP (see figure 1).

Other authors have also described increased risk of intellectual disability in children with CP born at term, compared with those born VPT, ${ }^{13}$ yet a large European study of CP reported little variation in 'impairment index' (a combination of motor, and/or intellectual, and/or associated impairments) with either GA or birth weight. ${ }^{27}$ Findings from our study however prompt consideration as to why term infants with BSCP are more at risk of severe intellectual disability than those born VPT.
When considering brain development, cortical neurogenesis predominates in the first trimester, involving proliferation, migration and organisation of neuronal precursor cells. ${ }^{28}$ From the late second and third trimesters, axonal and dendrite growth, synapse formation, and myelination predominate, which persists postnatally. ${ }^{28} \mathrm{~A}$ fourfold increase in brain growth during the third trimester has been demonstrated. ${ }^{29}$ It may be that interruptions during this later critical phase in brain development have more profound effects on intellectual functioning than earlier insults. Additionally, mechanisms of neuroplasticity are potentially more prevalent during early development; a less mature fetal brain may be better able to recover from early damage, compensate and reorganise, compared with a term infant's more developed brain. ${ }^{216}$

A recent European neuroimaging study in children with $\mathrm{CP}$ highlighted that most children with $\mathrm{CP}$ born preterm present with lesions that are typically originated around their GA at birth. ${ }^{30}$ Conversely, among children with CP born at term, less than a third (30\%) displayed lesions that originated around the time of their birth. This suggests the brain development disruptions responsible for $\mathrm{CP}$ among infants with $\mathrm{CP}$ born at term may stem from an early compromise or genetic anomalies. For this reason, perinatal and neonatal care and interventions may be ineffective in countering the causes of brain maldevelopment of term-born infants with CP. Conversely, preterm infants with $\mathrm{CP}$ may be more responsive to perinatal and neonatal care interventions. Linked with this 'amenability to intervention', it may be that the more severe the motor impairment, the greater the impact on the child's ability to adapt to and explore their environment during pivotal periods of early development, leading to further difficulties in intellectual functioning.

A higher risk of intellectual disability in infants with $\mathrm{CP}$ and small for gestational age (SGA) was also evident in our data. Higher risk of intellectual disability has been noted for SGA children. ${ }^{31}$ Our analyses did not indicate the risk associated with SGA varied across BSCP and USCP.

A limitation of this study, although common practice in population-based registry research, ${ }^{32}$ lies in our indicator of intellectual disability being typically based on a clinician's 'impression' of the child rather than a standardised test, as limitations in motor, sensory and communication abilities of children with CP result in difficulties completing such tests. ${ }^{33}$ To our knowledge, only one total population study ${ }^{7}$ has employed standardised scales to assess intellectual function in a total population of children with $\mathrm{CP}$ of all motor types. The latter study ${ }^{7}$ reported severe intellectual disability in $21 \%$ of the 127 children assessed, slightly lower than the 27\% reported for our sample of children with spastic CP. Although relying on clinician report of intellectual disability may present significant potential for bias, it reduces the emphasis on IQ score alone in line with various recommendations; it may thus represent a more holistic approach to diagnosis of intellectual disability. ${ }^{35} \mathrm{~A}$ further limitation is represented by the lack of detailed information regarding birth complications and cerebral lesions; we thus did not have information on variables that might bias or confound the association between the exposure and the outcome. ${ }^{36}$

Strengths of this study include the large sample size from a long-running national $\mathrm{CP}$ register that adheres to the SCPE standards and definitions. We used robust statistical methods to control for cohort variability and bias due to missing information. 


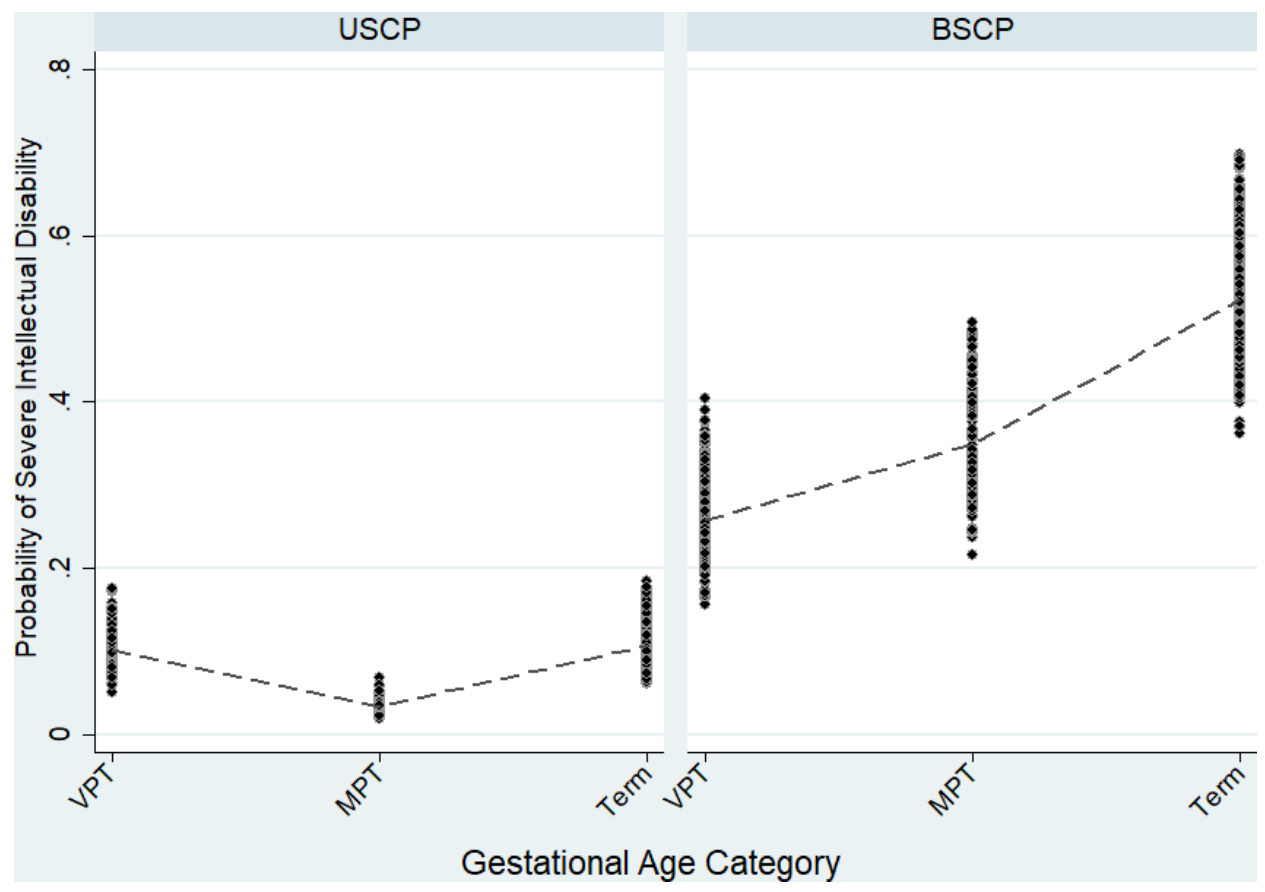

Figure 1 Predicted probability of severe intellectual disability by cerebral palsy subtype and gestational age category. Dots represent the distribution of predicted probabilities; dashed lines represent the average predicted probabilities by gestational age categories. BSCP, bilateral spastic cerebral palsy; MPT, moderately preterm (ie, 32-36 completed weeks gestation); term (ie, $\geq 37$ weeks gestation); USCP, unilateral spastic cerebral palsy; VPT, very preterm (ie, <32 completed weeks gestation).

\section{CONCLUSION}

Severe intellectual disability occurs in over a quarter of all children with spastic CP, with term-born children with BSCP being most at risk. Our results highlight the need to screen for severe intellectual disability in children with CP, particularly those with BSCP born at term. This will enable healthcare professionals to identify children in this 'at risk' group, facilitating early referral to appropriate specialists and informed conversations with families in relation to future nursery and educational placements for their child.

Twitter David Cummins @dcumminsno9, Claire Kerr @CKerrPhysio and Oliver Perra @oliver_perra

Acknowledgements We thank all the children with cerebral palsy and their families and healthcare professionals who notify and contribute data to the NICPR. We also wish to acknowledge the contributions of all NICPR staff, past and present. Finally, we acknowledge ongoing funding for the NICPR from the Northern Ireland Public Health Agency. We thank the members of the NICPR Advisory Committee for their helpful comments on an early draft of this manuscript.

Contributors $D C$ contributed to interpretation of findings and wrote the manuscript. OP co-manages the Northern Ireland Cerebral Palsy Register, developed the paper proposal, carried out data analysis, contributed to interpretation of findings and made edits to the manuscript. CK co-manages the Northern Ireland Cerebral Palsy Register, assisted with development of the paper proposal, and contributed to interpretation of findings and writing of the manuscript. KM assisted with development of the paper proposal and made edits to the manuscript. All authors approved the final version of the manuscript.

Funding The Northern Ireland Cerebral Palsy Register is funded by the Public Health Agency, Northern Ireland.

Disclaimer The funder had no role in the study design, execution, analyses, interpretation of data or decision to submit the results.

Competing interests $\mathrm{CK}$ and $\mathrm{KM}$ have received research funding from the Medical Research Council Proximity to Discovery Scheme supporting academicindustry collaboration.

Patient consent for publication Not required.
Ethics approval Ethics approval for the Northern Ireland Cerebral Palsy Register was granted by the Office for Research Ethics Committees Northern Ireland (ORECNI, Ref: 18/NI/0180).

Provenance and peer review Not commissioned; externally peer reviewed.

Data availability statement Data may be obtained from a third party and are not publicly available. Owing to conditions of ethical approval and data access agreements with Health and Social Care Trusts, data are not open access. Specific requests in relation to accessing data or collaborating with the Northern Ireland Cerebral Palsy Register can be sent to the corresponding author.

Supplemental material This content has been supplied by the author(s). It has not been vetted by BMJ Publishing Group Limited (BMJ) and may not have been peer-reviewed. Any opinions or recommendations discussed are solely those of the author(s) and are not endorsed by BMJ. BMJ disclaims all liability and responsibility arising from any reliance placed on the content. Where the content includes any translated material, BMJ does not warrant the accuracy and reliability of the translations (including but not limited to local regulations, clinical guidelines, terminology, drug names and drug dosages), and is not responsible for any error and/or omissions arising from translation and adaptation or otherwise.

Open access This is an open access article distributed in accordance with the Creative Commons Attribution Non Commercial (CC BY-NC 4.0) license, which permits others to distribute, remix, adapt, build upon this work non-commercially, and license their derivative works on different terms, provided the original work is properly cited, appropriate credit is given, any changes made indicated, and the use is non-commercial. See: http://creativecommons.org/licenses/by-nc/4.0/.

\section{ORCID iD}

Claire Kerr http://orcid.org/0000-0003-2067-5091

\section{REFERENCES}

1 Rosenbaum P, Paneth N, Leviton A, et al. A report: the definition and classification of cerebral palsy April 2006. Dev Med Child Neurol Suppl 2007;109:8-14.

2 O'Shea TM, O'Shea TM. Diagnosis, treatment, and prevention of cerebral palsy. Clin Obstet Gynecol 2008;51:816-28.

3 Sellier E, Platt MJ, Andersen GL, et al. Decreasing prevalence in cerebral palsy: a multi-site European population-based study, 1980 to 2003. Dev Med Child Neurol 2016:58:85-92.

4 Cerebral Palsy Alliance Research Institute. Report of the Australian cerebral palsy register birth years 1995-2012, 2018. Available: https://cpregister.com/wp-content/ 
uploads/2019/02/Report-of-the-Australian-Cerebral-Palsy-Register-Birth-Years-19952012.pdf

5 Cans C. Surveillance of cerebral palsy in Europe: a collaboration of cerebral palsy surveys and registers. Dev Med Child Neurol 2000;42:816-24.

6 Maenner MJ, Blumberg SJ, Kogan MD, et al. Prevalence of cerebral palsy and intellectual disability among children identified in two U.S. national surveys, 2011 2013. Ann Epidemiol 2016;26:222-6.

7 Sigurdardottir S, Eiriksdottir A, Gunnarsdottir E, et al. Cognitive profile in young Icelandic children with cerebral palsy. Dev Med Child Neurol 2008;50:357-62.

8 Türkoğlu G, Türkoğlu S, Çelik C, et al. Intelligence, functioning, and related factors in children with cerebral palsy. Noro Psikiyatr Ars 2017;54:S307.

9 Dalvand H, Dehghan L, Hadian MR, et al. Relationship between gross motor and intellectual function in children with cerebral palsy: a cross-sectional study. Arch Phys Med Rehabil 2012;93:480-4.

10 Casey BJ, Tottenham N, Liston C, et al. Imaging the developing brain: what have we learned about cognitive development? Trends Cogn Sci 2005;9:104-10.

11 Thelen E. Motor development. A new synthesis. Am Psychol 1995;50:79-95.

12 Himmelmann K, Beckung E, Hagberg G, et al. Gross and fine motor function and accompanying impairments in cerebral palsy. Dev Med Child Neurol 2006;48:417-23.

13 Reid SM, Meehan EM, Arnup SJ, et al. Intellectual disability in cerebral palsy: a population-based retrospective study. Dev Med Child Neurol 2018;60:687-94.

14 Kinsner-Ovaskainen A, Lanzoni M, Delobel M. Development of the JRC-SCPE central database and public health indicators, Eur 28935 en. Luxembourg: Publications office of the European Union, 2017

15 Schieve LA, Tian LH, Rankin K, et al. Population impact of preterm birth and low birth weight on developmental disabilities in US children. Ann Epidemiol 2016;26:267-74.

16 Hemming K, Colver A, Hutton JL, et al. The influence of gestational age on severity of impairment in spastic cerebral palsy. J Pediatr 2008:153:203-8.

17 Dolk H, Parkes J, Hill N. Trends in the prevalence of cerebral palsy in Northern Ireland, 1981-1997. Dev Med Child Neurol 2006;48:406-12.

18 Gutbrod T, Wolke D, Soehne B, et al. Effects of gestation and birth weight on the growth and development of very low birthweight small for gestational age infants: a matched group comparison. Arch Dis Child Fetal Neonatal Ed 2000;82:208F-14.

19 Sung IK, Vohr B, Oh W. Growth and neurodevelopmental outcome of very low birth weight infants with intrauterine growth retardation: comparison with control subjects matched by birth weight and gestational age. J Pediatr 1993;123:618-24.

20 Costantine MM, Lai Y, Bloom SL, et al. Population versus customized fetal growth norms and adverse outcomes in an intrapartum cohort. Am J Perinatol 2013:30:335-42.
21 Glinianaia SV, Jarvis S, Topp M, et al. Intrauterine growth and cerebral palsy in twins: a European multicenter study. Twin Res Hum Genet 2006;9:460-6.

22 Palisano R, Rosenbaum P, Walter $\mathrm{S}$, et al. Development and reliability of a system to classify gross motor function in children with cerebral palsy. Dev Med Child Neurol 2008;39:214-23.

23 Palisano RJ, Avery L, Gorter JW, et al. Stability of the gross motor function classification system, manual ability classification system, and communication function classification system. Dev Med Child Neurol 2018:60:1026-32.

24 Carpenter J, Kenward M. Multiple imputation and its application. New York: Wiley, 2012.

25 Sterne JAC, White IR, Carlin JB, et al. Multiple imputation for missing data in epidemiological and clinical research: potential and pitfalls. BMJ 2009;338:b2393.

26 Rubin DB. Multiple imputation for nonresponse in surveys. New York: Wiley, 1987.

27 Horber V, Fares A, Platt MJ, et al. Severity of cerebral Palsy-The impact of associated impairments. Neuropediatrics 2020:51:120-8.

28 Clouchoux C, Guizard N, Evans AC, et al. Normative fetal brain growth by quantitative in vivo magnetic resonance imaging. Am J Obstet Gynecol 2012;206:173.e1-173.e8

29 Bouyssi-Kobar M, du Plessis AJ, McCarter R, et al. Third trimester brain growth in preterm infants compared with in utero healthy fetuses. Pediatrics 2016;138:e20161640.

30 Horber V, Sellier E, Horridge K, et al. The origin of the cerebral palsies: contribution of population-based neuroimaging data. Neuropediatrics 2020;51:113-9.

31 Chen R, Tedroff K, Villamor E, et al. Risk of intellectual disability in children born appropriate-for-gestational-age at term or post-term: impact of birth weight for gestational age and gestational age. Eur J Epidemiol 2020;35:273-82.

32 Stadskleiv K, Jahnsen R, Andersen GL, et al. Neuropsychological profiles of children with cerebral palsy. Dev Neurorehabil 2018:21:108-20.

33 Ballester-Plané J, Laporta-Hoyos O, Macaya A, et al. Measuring intellectual ability in cerebral palsy: the comparison of three tests and their neuroimaging correlates. Res Dev Disabil 2016;56:83-98

34 Stadskleiv K. Cognitive functioning in children with cerebral palsy. Dev Med Child Neurol 2020:62:283-9.

35 van Bakel M, Einarsson I, Arnaud C, et al. Monitoring the prevalence of severe intellectual disability in children across Europe: feasibility of a common database. Dev Med Child Neurol 2014;56:361-9.

36 Ananth CV, Schisterman EF. Confounding, causality, and confusion: the role of intermediate variables in interpreting observational studies in obstetrics. Am J Obstet Gynecol 2017;217:167-75. 